\section{A novel method for in situ measurement of solubility via impedance scanning quartz crystal microbalance studies}

\author{
Christoph Stock, Dominik Moosbauer, Sandra Zugmann, Tobias Simbeck, Marius Amereller \\ and Heiner Jakob Gores*
}

Received 1st February 2011, Accepted 4th May 2011

DOI: $10.1039 / \mathrm{c1cc10642b}$

We introduce here a novel in situ measurement method for solubility of solids in various liquids. Without any calibration the saturation point can be obtained in a relative manner. We exemplified the new method at four systems including water, organic carbonates and an ionic liquid as the solvents and various salts as dissolved solids.

Solubility is a key property in many fields of research, ${ }^{1}$ including biological, ${ }^{2}$ medical ${ }^{3}$ and technical applications. ${ }^{4}$ For example, in lithium-ion batteries the solubility of lithium salts in blends of organic solvents affects the battery performance via the conductivity of the electrolyte, its useful operating temperature range, the build-up of the solid electrolyte interface $(\mathrm{SEI})^{5}$ and concentration polarization during battery discharge.

The quartz crystal microbalance (QCM) is a method to detect minute mass changes on the surface of an electroacoustical sensor device by detecting changes of its resonance behavior. The QCM is commonly used in all sectors of applied research. This technique is of great value not only in bioanalytical and life science research ${ }^{6,7}$ but also in materials science and electrochemical research including electrochemical metal deposition, ${ }^{8,9}$ metal corrosion studies,${ }^{10}$ as well as for investigations of corrosion prevention, electropolymerization of conducting polymers $^{11,12}$ and study of intercalation electrodes. ${ }^{13,14}$ With QCM it is possible to study various processes at surfaces as well as changes in viscosity and density of the liquid at the interface. $^{15}$

We present here a novel method that is able to measure the solubility of solid materials in liquids. As our group is mainly interested in electrolytes to demonstrate the usefulness of the technique we restricted this first study to solubility measurements of potassium chloride $(\mathrm{KCl})$ in water, two lithium salts in blends of organic solvents (lithium tetrafluoroborate $\left(\mathrm{LiBF}_{4}\right)$, lithium difluoromono(oxalato)-borate (LiDFOB)), and $\mathrm{LiBF}_{4}$ in an ionic liquid (IL), i.e. (1-ethyl-3-methylimidazolium tetrafluoroborate $\left.\left(\mathrm{EMImBF}_{4}\right)\right)$.

The solubility value obtained from the QCM data was compared with values from the literature or with conductivity measurements. All the measurements were realized in situ.

Institut für Physikalische und Theoretische Chemie,

Universität Regensburg, D93053 Regensburg, Germany.

E-mail:heiner.gores@chemie.uni-regensburg.de
In contrast to other methods, no filtering process was necessary. ${ }^{16}$

As solvents we used Millipore grade water (Milli-Q, Millipore Corporation), a mixture of ethylene carbonate (EC) (Selectipur, Merck, Germany) and diethyl carbonate (DEC) (Selectipur, Merck, Germany) with mass friction EC: DEC equal to $3: 7$ and $\mathrm{EMImBF}_{4}$. The carbonate based solvent was set up in an inert gas atmosphere with a moisture content $<0.8 \mathrm{ppm}$ and oxygen content $<10 \mathrm{ppm}$. The water content of the EC: DEC ( $3: 7)$ blend was measured by Karl-Fischer titration (Mettler, type Karl Fischer titrator DL18) yielding 50 ppm. The IL, which was synthesized and analyzed in our labs, showed $23 \mathrm{ppm}$ water and $26 \mathrm{ppm}$ chloride. For studies on aqueous systems we did chose potassium chloride $(\mathrm{KCl})$ (p.A., Merck, Germany) The solid for the nonaqueous solutions was lithium tetrafluoroborate $\left(\mathrm{LiBF}_{4}\right)$ (battery grade, Stella Chemifa Corporation, Japan). The LiDFOB was synthesized in our labs by a recent synthesis route, ${ }^{17}$ purity $>99 \%$.

For our measurements we used gold-sputtered quartz $(6 \mathrm{MHz}$ standard resonance frequency; Eller). The QCM device has been described by Wudy et al. ${ }^{12}$ Solubility measurements of aqueous solvents were performed in a Teflon ${ }^{\circledR}$ cell (Fig. 1a), with an inner volume of about $4 \mathrm{~mL}$. The quartz crystal is mounted at the front side of the Teflon ${ }^{\circledR}$ chamber by use
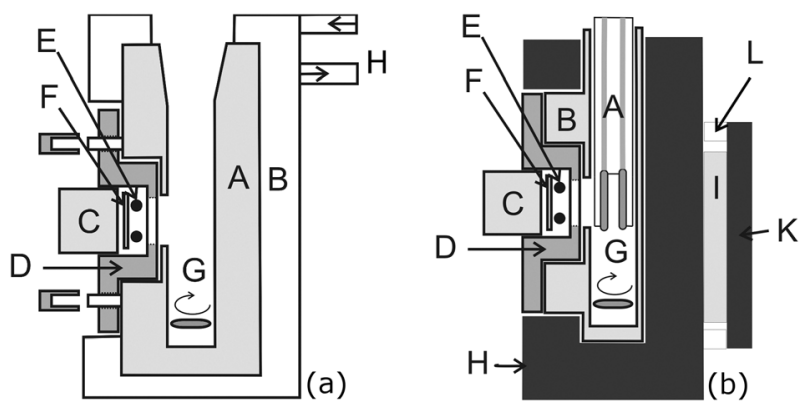

Fig. 1 Measurement cells for aqueous (a) and non-aqueous solvents (b). Common parts: C: PEEK screw, D: stainless steel device for holding the quartz, E: FFKM O-ring, F: quartz crystal, G: magnetic stirrer. Components in (a): A: Teflon ${ }^{\circledR}$ chamber, B: aluminium jacket filled with thermocontrol fluid, $\mathrm{H}$ : in- and outlet for thermocontrol fluid. Components in (b): A: conductivity measurement cell, B: PEEK chamber, $\mathrm{H}$ : copper jacket, I: Peltier element, K: heat sink (aluminium), L: isolation (Teflon ${ }^{\circledR}$ ). 
of a stainless steel device and a screw made of polyetheretherketone (PEEK). The PEEK screw has two gold contacts to apply the AC-signal on the backside of the quartz crystal. The sensitive part of the crystal is inside the chamber. The steel device is acting as ground, so we are able to induce the oscillation of the quartz. To seal the holder, we used a perfluorinated rubber ring. The Teflon ${ }^{\circledR}$ chamber has an aluminium jacket, where the thermostatting liquid, silicon oil, is circulated by ministat cc3 (Peter Huber Kälte-maschinenbau GmbH, Germany) to control temperature. For the measurement in non-aqueous solvents a cell (Fig. 1b) was built from PEEK with a copper jacket which was thermostatted by use of a Peltier element. The temperature regulator was home built. In addition to the collection of resonance frequencies of the quartz, in situ conductivity measurements were done using a LF 597-s (WTW, Germany) conductivity meter and a conductivity cell (Methrom AG, Switzerland), cell constant $1.061 \mathrm{~cm}^{-1}$. The whole cell was kept under an inert gas atmosphere, which was flushed with nitrogen gas dried by Sicapent ${ }^{\circledR}$ (Merck, Germany) from our in-house feed line.

The in-house built cells (Fig. 1) were filled with about $2 \mathrm{~mL}$ of pure solvent and kept at constant temperature $(298 \pm 0.02) \mathrm{K}$. After establishing a stable series resonance frequency $f_{\mathrm{s}}$ it was recorded for several minutes, so that a statistical evaluation was possible. After this period, a small amount of solid was added to the mixture. When a new frequency plateau was reached for at least 20 minutes and after the solution was stirred for at least 1 hour another part of solid was added. The added mass was determined by weighing (Mettler Toledo balance AB204, Germany). During measurements the liquids were stirred, at a rate which did not affect quartz oscillation.

In Fig. 2 a typical result for the QCM experiment is shown. The initial state is observed from $0 \mathrm{~s}$ up to $t_{0}$. At time $t_{0}$ a small amount of salt is added to the cell. Then the dissolution takes place. A new equilibrium is reached, when the slope of the frequency as a function of time is equal to or near zero. The decrease in series resonance frequency can be explained by Kanazawa's law, see eqn (1).

$$
\Delta f=-f_{0}^{3 / 2}\left(\frac{\eta \rho}{\pi \mu_{\mathrm{Q}} \rho_{\mathrm{Q}}}\right)
$$

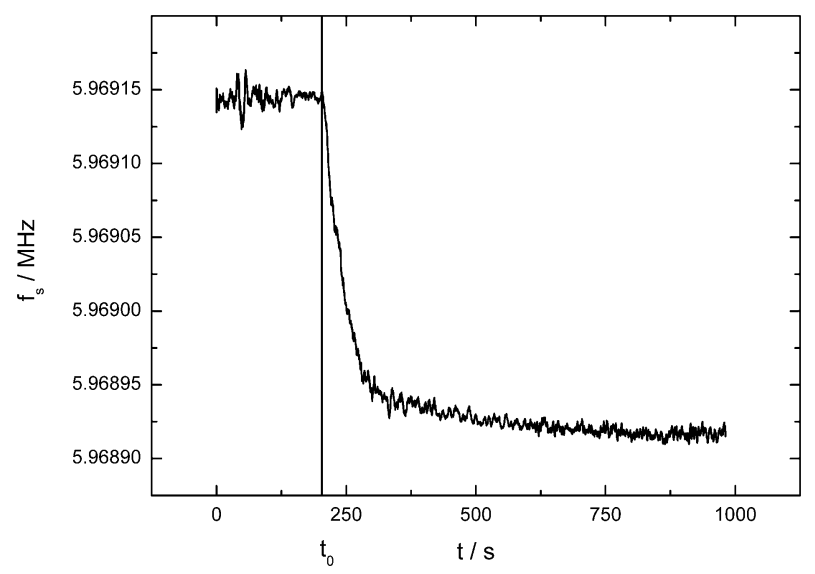

Fig. 2 Typical measurement curve; observation of series resonance frequency $f_{\mathrm{s}}$ after adding some salt at time $t_{0}$ to the solution, here LiDFOB to EC: DEC $(3: 7)$.

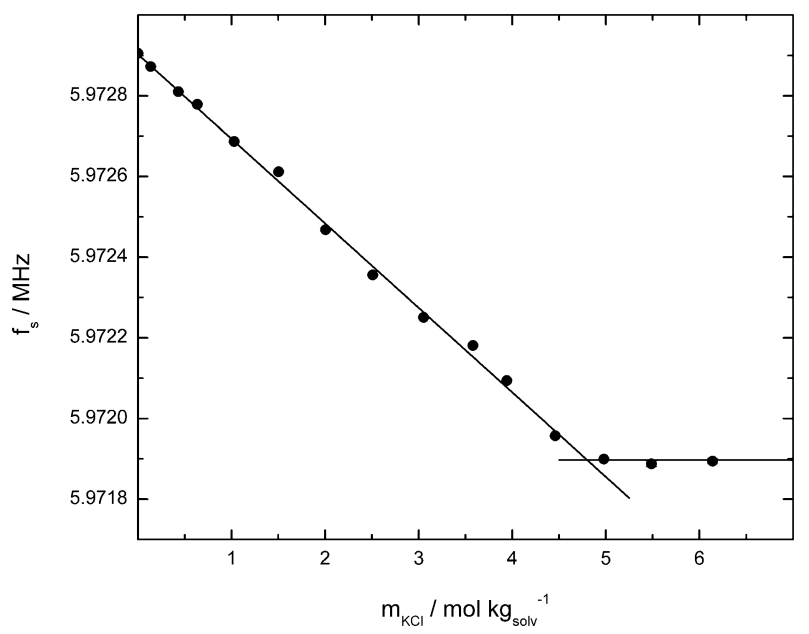

Fig. 3 Solubility measurement of $\mathrm{KCl}$ in water by detecting the series resonance frequency $f_{\mathrm{s}}$ in $\mathrm{MHz}(\bullet)$ plotted against the molarity $m$ in $\mathrm{mol} \mathrm{kg}_{\text {solv }}{ }^{-1}$. The fitted functions are plotted as a solid line.

In eqn (1) the frequency shift $\Delta f$ is described by use of the fundamental resonance frequency $f_{0}$, the dynamic viscosity $\eta$, and the density $\rho$ of the fluid, which is in contact with the quartz surface. The parameter $\rho_{\mathrm{Q}}$ is the quartz's density $\left(2.648 \mathrm{~g} \mathrm{~cm}^{-3}\right)$ and $\mu_{\mathrm{Q}}$ is its shear modulus $\left(2.974 \times 10^{11} \mathrm{~g} \mathrm{~cm}^{-1} \mathrm{~s}^{-2}\right)$. By increasing the salt concentration of the solution, the product of density and viscosity increases and causes a decrease in resonance frequency. When the solubility limit is reached addition of further solid has a negligible influence on the resonance frequency of the oscillating quartz. Fig. 3 shows the measured frequencies plotted against the molarity $m$ of the salt in mol kg-1 for the system $\mathrm{KCl}$ and water at $298 \pm 0.02 \mathrm{~K}$.

In this case, decreasing values of the plotted curve in Fig. 3 can be fitted as a line. The three final points at 5 to $6.2 \mathrm{~mol} \mathrm{~kg}^{-1}$ were assumed as a line with a slope equal to zero. The intersection point of these two lines yields the solubility of the solid. For our test system $\mathrm{KCl}$ dissolved in water we obtained a solubility value of $4.8367 \pm 0.0028 \mathrm{~mol} \mathrm{~kg}^{-1}$, which is in agreement with the literature value of $4.83 \mathrm{~mol} \mathrm{~kg}^{-1} \cdot 18$

For other systems it was necessary to increase the order of the polynomial function for fitting data before reaching the solubility limit. To test our new method for non-aqueous systems we used a carbonate based solvent blend and two lithium salts, $\mathrm{LiBF}_{4}$ and LiDFOB, which were dissolved in the liquid phase. The solubility values evaluated from the QCM data are shown in Fig. 2. For verifying our measured data for lithium salts, we chose conductivity measurements. We knew from our previous work ${ }^{10}$ that the conductivity $\kappa$ of carbonate based lithium salts electrolytes can be described by the Casteel-Amis equation (eqn (2)). ${ }^{19}$ When reaching the solubility limit the conductivity should not change, because the concentration of salt will be kept constant.

$$
\kappa=\kappa_{\max }\left(\frac{m}{\mu}\right)^{a} \exp \left[b(m-\mu)^{2}-\frac{a}{\mu}(m-\mu)\right]
$$

In eqn (2) $\kappa_{\max }$ is the maximum conductivity at the corresponding molarity $\mu$ in $m / \mathrm{mol} \mathrm{kg}_{\text {solv }^{-1}}{ }^{-1} a$ and $b$ are parameters without any physical meaning. 


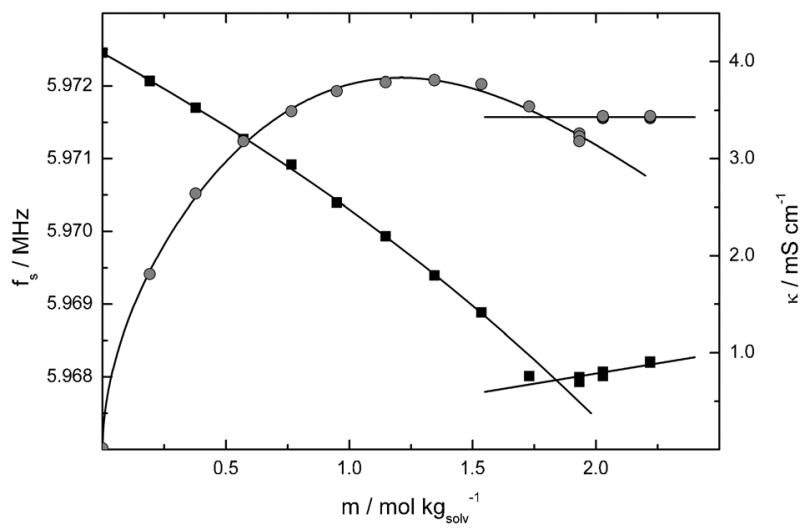

Fig. 4 Solubility measurement of LiDFOB in EC: DEC (3:7); series resonance frequency $f_{\mathrm{s}}(\boldsymbol{\square})$ on the left side is plotted against molarity $m$. The relative conductivity $\kappa(\bullet)$ is plotted on the right side against the molarity $m$. The fitted functions are plotted as a line.

For concentrations near to saturation we did measure conductivity and frequency at $298 \mathrm{~K}$, then we heated the solution up to $308 \mathrm{~K}$ for 1 hour and cooled it down again to $298 \mathrm{~K}$ to ensure that supersaturation did not occur. When the same value before and after heating was obtained, we accepted this final solubility value.

Fig. 4 shows the series resonance frequency $f_{\mathrm{s}}$ of the oscillating quartz and the specific conductivity $\kappa$ plotted against molarity $m$ of the salt. Starting at lower concentration and increasing the concentration of salt, a discontinuity in both curves is observed, when reaching the solubility limit (see Table 1). In this case, QCM data before saturation were fitted to a cubic polynomial. Concerning the specific conductivity up to saturation described by the Casteel-Amis equation (eqn (2)) and after saturation both conductivity and QCM data are fitted by straight lines. The observed increase in frequency may be also affected by some suspended salt raised by the magnetic stirrer. The intersection points again give us the solubility values for the two different methods.

For checking the method for very viscous media we did chose an IL, here EMImBF 4 as a solvent and $\mathrm{LiBF}_{4}$ as a solute. Measured data were treated and evaluated in the same manner as for the carbonate based electrolytes. A polynomial function of 2 nd order was fitted to frequency and specific conductivity data before the saturation point is reached. The region with a higher salt content was for both methods again fitted with a line. The intersection point of the parabola with the line results in the saturation point, the solubility.

Again for this very viscous system the solubility values agree nicely (see Table 1). The larger deviation is caused by higher viscosity entailing a higher noise level on the oscillating frequency. Therefore the accuracy is lower, but acceptable. To sum up, determination of solubility with our recently presented fast impedance scanning quartz crystal micro-balance in combination with conductivity measurements is possible. Comparison of
Table 1 List of solubility values in molarity $m\left(\mathrm{~mol} \mathrm{~kg}^{-1}\right)$

\begin{tabular}{|c|c|c|c|}
\hline System & $m_{\mathrm{QCM}}$ & $T / \mathrm{K}$ & Reference value for $m$ \\
\hline $\mathrm{KCl} /$ water & $4.8367 \pm 0.0028$ & 298 & $4.83,{ }^{18} 4.8297^{a, 20}$ \\
\hline $\mathrm{LiBF}_{4} / \mathrm{EC}: \mathrm{DEC}$ & $2.8802 \pm 0.0032$ & 298 & $2.80 \pm 0.28^{b}$ \\
\hline $\mathrm{LiDFOB} / \mathrm{EC}: \mathrm{DEC}$ & $1.804 \pm 0.035$ & 298 & $1.792 \pm 0.027^{b}$ \\
\hline $\mathrm{LiBF}_{4} / \mathrm{EMImBF}_{4}$ & $2.644 \pm 0.093$ & 298 & $2.94 \pm 0.12^{b}$ \\
\hline
\end{tabular}

values obtained by QCM measurements with literature values for the aqueous system (water and potassium chloride) shows very good agreement. Solubility obtained from conductivity measurements and QCM measurements for non-aqueous electrolytes are in sufficient agreement, too. Only for ILs as a liquid phase the uncertainty of the determined solubility was increased, due to the large viscosity of the system. In addition, the design of our cells already suggests us to anticipate that also temperature dependent values of the solubility can be obtained under protecting atmosphere.

Editing by Prof. Dr G. T. Hefter, University of Murdoch, Australia, and financial support from the German Research Foundation (DFG) contract numbers 563861 (A new microapparatus for measurements of gas solubility) and 544243 (Project Initiative PAK 177) are gratefully acknowledged.

\section{Notes and references}

1 G. T. Hefter and R. P. T. Tomkins, The experimental determination of solubilities, Wiley Ser. Solution Chem.Wiley, Chichester, 2003.

2 A. Shalmashi and A. Eliassi, J. Chem. Eng. Data, 2008, 53, 199.

3 C. A. Lipinski, F. Lombardo, B. W. Dominy and P. J. Feeney, Adv. Drug Delivery Rev., 1997, 23, 3.

4 K. Wagner, T. Friese, S. Schulz and P. Ulbig, J. Chem. Eng. Data, 1998, 43, 871.

5 K. Tasaki and S. J. Harris, J. Phys. Chem. C, 2010, 114, 8076.

6 Z. Shen, M. Huang, C. Xiao, Y. Zhang, X. Zeng and P. G. Wang, Anal. Chem., 2007, 79, 2312.

7 A. Janshoff and C. Steinem, Sens. Update, 2001, 9, 313.

8 A. Bund and A. Ispas, J. Electroanal. Chem., 2005, 575, 221.

9 F. Wudy, M. Multerer, C. Stock, G. Schmeer and H. J. Gores, Electrochim. Acta, 2008, 53, 6568.

10 D. Moosbauer, S. Zugmann, M. Amereller and H. J. Gores, J. Chem. Eng. Data, 2010, 55, 1794.

11 Q. Xie, Z. Li, C. Deng, M. Liu, Y. Zhang, M. Ma, S. Xia, X. Xiao, D. Yin and S. Yao, J. Chem. Educ., 2007, 84, 681.

12 F. Wudy, T. Schedlbauer, C. Stock and H. J. Gores, Acta Chim. Slov., 2009, 56, 65.

13 O. Bohnke, B. Vuillemin, C. Gabrielli, M. Keddam, H. Perrot, H. Takenouti and R. Torresi, Electrochim. Acta, 1995, 40, 2755.

14 D. A. Buttry and M. D. Ward, Chem. Rev., 1992, 92, 1355.

15 K. K. Kanazawa and J. G. Gordon, Anal. Chim. Acta, 1985, $175,99$.

16 A. Patel, A. Vaghasiya, R. Gajera and S. Baluja, J. Chem. Eng. Data, 2010, 55, 1453.

17 C. Schreiner, M. Amereller and H. J. Gores, Chem.-Eur. J., 2009, 15,2270 .

18 A. Kolker and J. J. de Pablo, Chem. Eng. Sci., 1995, 50, 1953.

19 J. F. Casteel and E. S. Amis, J. Chem. Eng. Data, 1972, 17, 55.

20 S. P. Pinho and E. A. Macedo, J. Chem. Eng. Data, 2005, 50, 29. 